Article

\title{
Structure and Anti-Inflammatory Activity of a New Unusual Fucosylated Chondroitin Sulfate from Cucumaria djakonovi
}

\author{
Nadezhda E. Ustyuzhanina ${ }^{1, *}$, Maria I. Bilan ${ }^{1}$, Elena G. Panina ${ }^{2}$, Nadezhda P. Sanamyan ${ }^{2}$, \\ Andrey S. Dmitrenok ${ }^{1}{ }^{(D}$, Eugenia A. Tsvetkova ${ }^{1}$, Natalia A. Ushakova ${ }^{3}$, \\ Alexander S. Shashkov ${ }^{1}$, Nikolay E. Nifantiev ${ }^{1}$ and Anatolii I. Usov ${ }^{1, *}$ \\ 1 N.D. Zelinsky Institute of Organic Chemistry, Russian Academy of Sciences, Leninsky prospect 47, \\ Moscow 119991, Russia; bilan@ioc.ac.ru (M.I.B.); dmt@ioc.ac.ru (A.S.D.); \\ e_tsvet@ioc.ac.ru (E.A.T.);shash@ioc.ac.ru (A.S.S.); nen@ioc.ac.ru (N.E.N.) \\ 2 Kamchatka Branch of Pacific Geographical Institute FEB RAS, Russian Academy of Sciences, \\ Petropavlovsk-Kamchatsky 683000, Russia; panina1968@mail.ru (E.G.P.); actiniaria@sanamyan.com (N.P.S.) \\ 3 V.N. Orekhovich Research Institute of Biomedical Chemistry, Pogodinskaya str. 10, Moscow 119121, Russia; \\ natalia.ushakova@ibmc.msk.ru \\ * Correspondence: ustnad@gmail.com (N.E.U.); usov@ioc.ac.ru (A.I.U.); Tel.: +7-495-135-8784 (N.E.U.)
}

Received: 12 September 2018; Accepted: 12 October 2018; Published: 17 October 2018

\begin{abstract}
Fucosylated chondroitin sulfate $\mathrm{CD}$ was isolated from the sea cucumber Cucumaria djakonovi collected from the Avachinsky Gulf of the eastern coast of Kamchatka. Structural characterization of CD was performed using a series of non-destructive NMR spectroscopic procedures. The polysaccharide was shown to contain a chondroitin core $[\rightarrow 3)-\beta$-D-GalNAc- $(1 \rightarrow 4)$ $\beta$-D-GlcA- $(1 \rightarrow]_{n}$ where about $60 \%$ of GlcA residues were 3-O-fucosylated, while another part of GlcA units did not contain any substituents. The presence of unsubstituted both at O-2 and O-3 glucuronic acid residues in a structure of holothurian chondroitin sulfate is unusual and has not been reported previously. Three different fucosyl branches Fuc 2 S S4S, Fucp3S4S and Fuc $p 4 S$ were found in the ratio of 2:1:1. The GalNAc units were mono- or disulfated at positions 4 and 6. Anti-inflammatory activity of $C D$ was assessed on a model of acute peritoneal inflammation in rats. About $45 \%$ inhibition was found for $\mathbf{C D}$, while a structurally related linear chondroitin sulfate $\mathbf{S S}$ from cartilage of the fish Salmo salar demonstrated only 31\% inhibition, indicating that the presence of sulfated fucosyl branches is essential for anti-inflammatory effect of chondroitin sulfates of marine origin.
\end{abstract}

Keywords: fucosylated chondroitin sulfate; Cucumaria djakonovi; sea cucumber; structure; anti-inflammatory activity

\section{Introduction}

The body walls of sea cucumbers contain two main types of sulfated polysaccharides, sulfated fucans (SF) often named "fucoidans" [1-6], and fucosylated chondroitin sulfates (FucCS). The latter polysaccharides isolated from different species of sea cucumbers are known to be composed of D-glucuronic acid, $N$-acetyl-D-galactosamine, L-fucose and sulfate residues [7]. The backbones of these polysaccharides are formed by repeating disaccharide units $\rightarrow 3)-\beta$-D-GalNAc- $(1 \rightarrow 4)-\beta$-D-GlcA- $(1 \rightarrow$, while L-fucosyl residues are attached as branches to O-3 of GlcA or O-6 of GalNAc of the backbones. The pattern of sulfation adds the species-to-species structural diversity of FucCS [8]. Thus, sulfate groups could be located at O-4 or both at O-4 and O-6 of GalNAc, at different positions of fucosyl branches, as well as at O-3 or both at O-2 and O-3 of GlcA [9-14]. The fine structure of FucCS depends on the species and significantly influences the type and level of biological activity, such as 
anticoagulant, antithrombotic, antitumor, etc. $[15,16]$. The anti-inflammatory activity is connected with the ability of FucCS to bind to P- and L-selectins [17]. It should be noted, however, that some data on the distinct correlations between structure of fucose branches and biological activity of FucCS are controversial [18].

About one hundred of holothurian species belonging to 3 subclasses, 5 orders, 16 families and 47 genera were found in the Far-Eastern seas of Russia [19]. Some of these species, such as Cucumaria djakonovi (family Cucumariidae, order Dendrochirotida), have potential commercial application as the high-value components of functional foods or the source of biologically active compounds, but chemical composition of the most of them was not investigated. The present communication describes structural characterization of a new type of FucCS isolated from the sea cucumber C. djakonovi and designated as CD. Anti-inflammatory properties of this polysaccharide were studied as well and compared with the corresponding activity of a linear chondroitin sulfate SS isolated from the fish Salmo salar.

\section{Results and Discussion}

Water-soluble polysaccharides were isolated from the body walls of C. djakonovi by conventional solubilization in the presence of papain [20] followed by treatment of the extract with cetyltrimethylammonium bromide to precipitate the sulfated components, which were then transformed into a water-soluble sodium salts by stirring with $\mathrm{NaI}$ in ethanol. The yield of the crude preparation of sulfated polysaccharides (SP) was $1.1 \%$ of wet body walls. It should be noted that, in addition to Fuc, GalN, GlcA and sulfate as the expected main components, SP contained also moderate amounts of Glc, Gal, GlcN and traces of Xyl and Man.

SP was, evidently, a mixture of several polysaccharides. It was resolved into four fractions using anion-exchange chromatography on a column containing DEAE(diethylaminoethyl)-Sephacel. Fractions were eluted with water followed by aqueous $\mathrm{NaCl}$ solutions of increasing concentrations. According to the molar ratio of the main components (Fuc:GlcA:GalNAc:SO $3 \mathrm{Na}, 11: 16: 16: 57$ ), fraction eluted with $1.0 \mathrm{M} \mathrm{NaCl}$ may be regarded as a preparation of FucCS, which will be further denoted as CD.

A preparation of usual vertebrate chondroitin sulfate SS was isolated from a crude extract of Salmo salar cartilage [21] using mild alkaline treatment followed by anion-exchange chromatography. Structure of SS was confirmed by coinciding of its NMR spectral characteristics with literature data for chondroitin sulfates A and C [21-23]. According to NMR spectra, the ratio between A and C units in SS was 0.8 (see Figures S1-S4).

Preliminary assessment of the molecular weights of CD and SS was performed by polyacrylamide gel electrophoresis (PAGE) in comparison with sulfated polysaccharides heparin (Sigma, St. Louis, MO, USA) and enoxaparin (Clexane ${ }^{\circledR}$, Sanofi, Paris, France) having defined molecular weight (MW) and used as standards (Figure 1). Thus, MW of heparin and enoxaparin were stated to be about $17 \mathrm{kDa}$ and $4.5 \mathrm{kDa}$, respectively, and the difference in MW was definitely seen on PAGE. Based on mobility of samples it was concluded that MW of CD was quite similar to that of heparin. More accurate estimation of MW was performed by TSK gel chromatography using an appropriate analytical column calibrated with pullulans. As a result, the molecular weight of CD was determined as $\sim 17.3 \mathrm{kDa}$. 


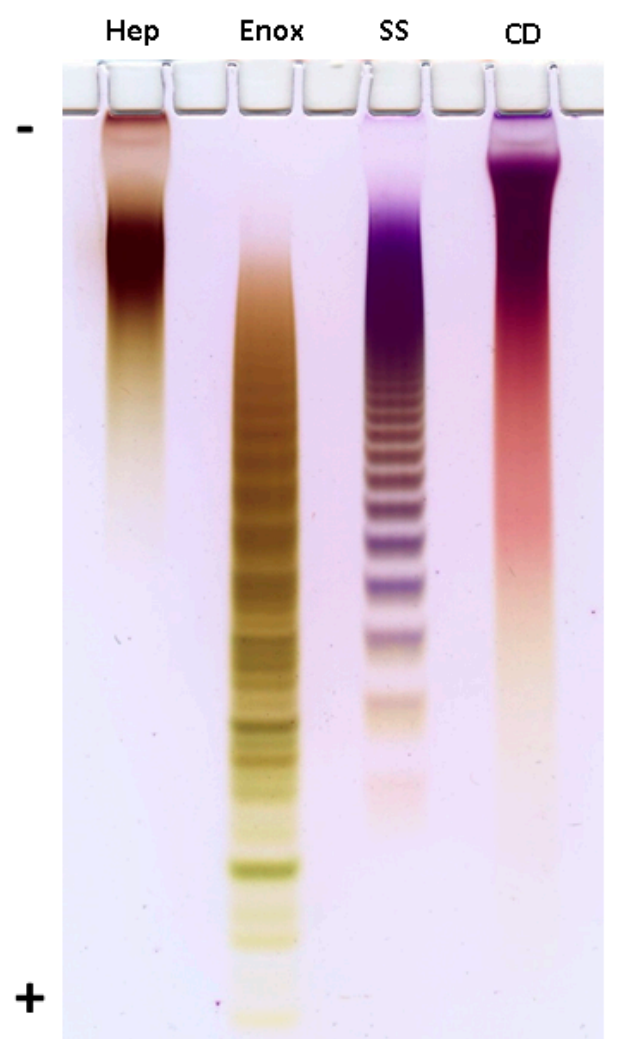

Figure 1. Electrophoresis in polyacrylamide gel. Hep-heparin (Sigma), Enox-enoxaparin (Clexane ${ }^{\circledR}$, Sanofi), SS—chondroitin sulfate from S. salar, CD—fucosylated chondroitin sulfate from C. djakonovi.

Further detailed characterization of the structure of polysaccharide CD was performed using a series of non-destructive NMR spectroscopic procedures. Analysis of the 1D NMR spectra confirmed the presence of $\mathrm{N}$-acetyl-galactosamine, uronic acid and fucose residues as the main monosaccharide components by the characteristic values of chemical shifts of C-2 ( $\delta 52.7 \mathrm{ppm})$ for GalNAc, and C-6 for Fuc $(\delta 16.9,17.2 \mathrm{ppm})$ and GlcA $(\delta 175.6-176.0 \mathrm{ppm})$ in the ${ }^{13} \mathrm{C}$ NMR spectrum, as well as of H-6 $(\delta 1.37 \mathrm{ppm})$ for Fuc in the ${ }^{1} \mathrm{H}$ NMR spectrum (Figures 2 and 3, Table 1 ).

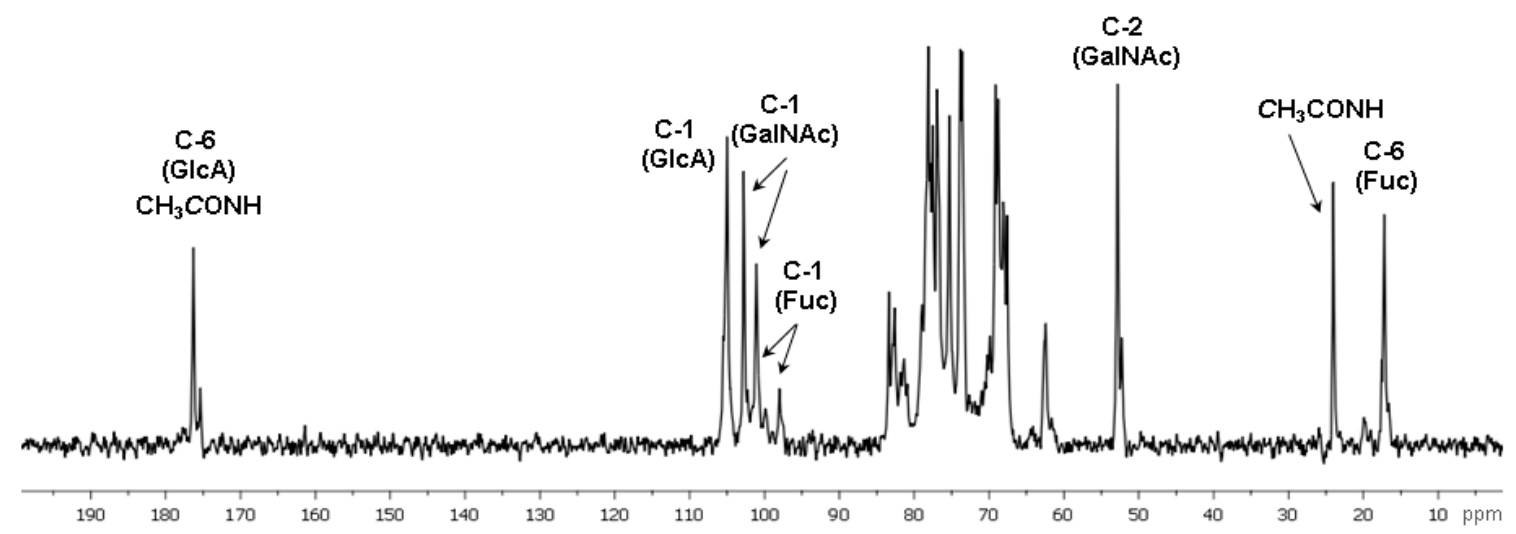

Figure 2. The ${ }^{13} \mathrm{C}$ NMR spectrum of fucosylated chondroitin sulfate CD. 


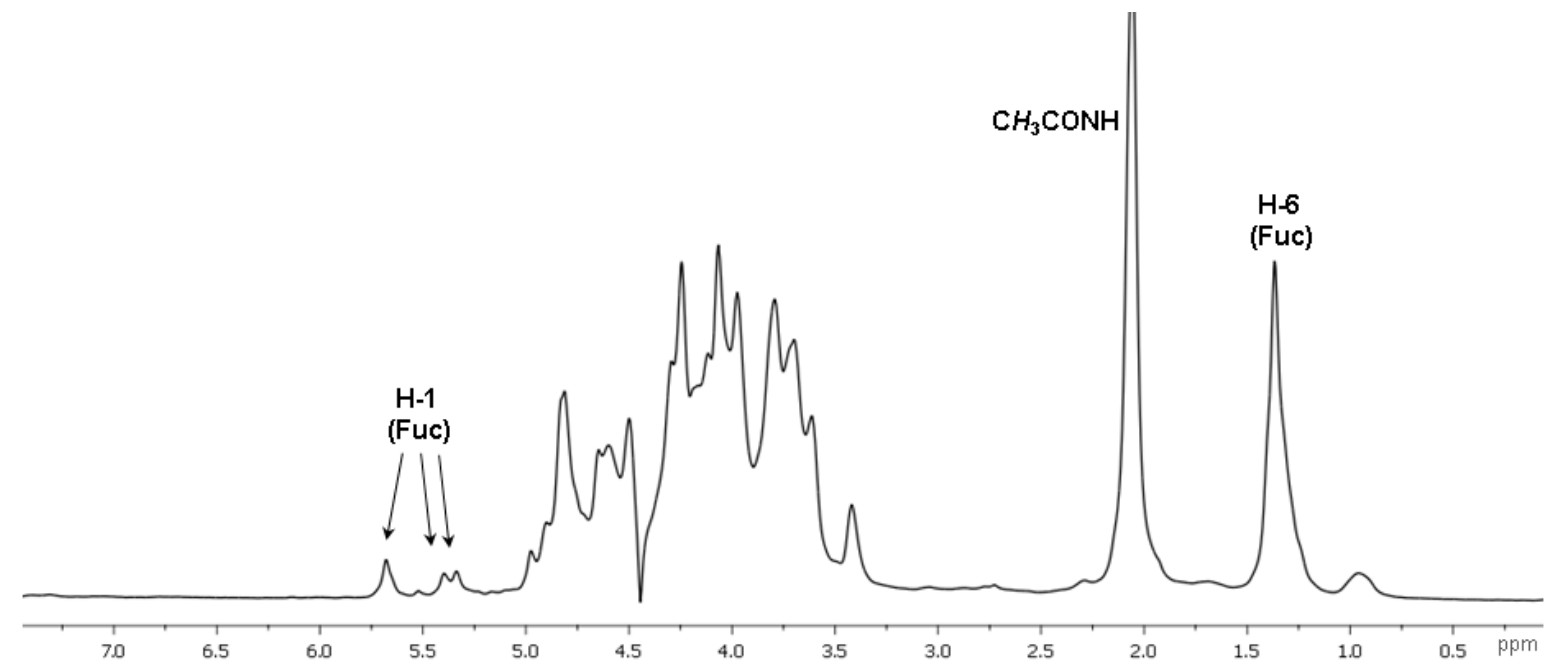

Figure 3. The ${ }^{1} \mathrm{H}$ NMR spectrum of fucosylated chondroitin sulfate $\mathrm{CD}$.
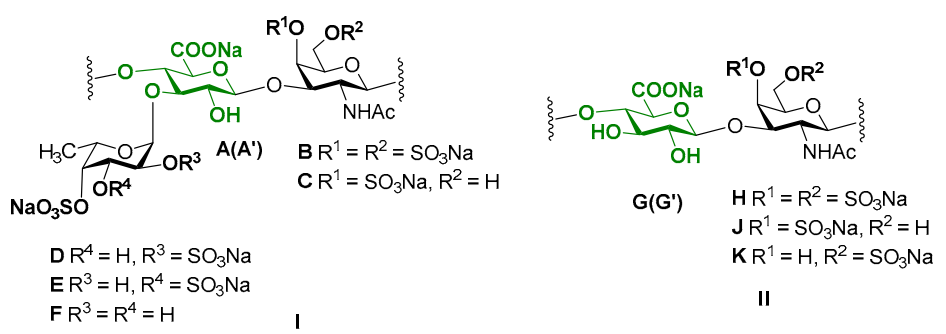

Figure 4. Repeating branched (I) and linear (II) blocks of fucosylated chondroitin sulfate CD (units A-K) and disaccharide components of chondroitin sulfate SS (units G, G', J, K). Unit A bears Fuc2S4S (D), whereas unit $\mathbf{A}^{\prime}$ bears Fuc3S4S (E) or Fuc4S (F). Unit $\mathbf{G}$ is linked to GalNAc4S6S (H) or GalNAc4S (J), whereas unit $\mathbf{G}^{\prime}$ is linked to GalNAc6S (K).

The 2D NMR experiments led to full assignment of all the signals in ${ }^{1} \mathrm{H}$ and ${ }^{13} \mathrm{C}$ NMR spectra and to reveal the fine structure of polysaccharide CD (Figure 4). There were six separated cross-peaks $\mathrm{H} 1 / \mathrm{C} 1$ in the anomeric region of the ${ }^{1} \mathrm{H}_{-}{ }^{13} \mathrm{C}$ HSQC NMR spectrum of $\mathrm{CD}$ (Figure 5A). Three of them at 5.69/97.7 ppm, 5.34/100.5 ppm and 5.41/99.6 ppm were related to fucosyl residues Fucp 2S4S (D), Fucp3S4S (E) and Fucp4S (F), respectively [9-14,17]. The assignment of signals in the spin-systems of units D-F was performed based on the data of the COSY, ROESY (Figure 5B, C), and TOCSY (Figure S4) spectra (Table 1). The downfield chemical shifts of the respective protons and carbons confirmed the pattern of sulfation of units D-F. The attachment of all fucosyl branches to O-3 of GlcA residues was confirmed by the correlation peaks H-1(Fuc)-H-3(GlcA) in the ROESY spectrum (Figure 5C). The ratio of D:E:F was determined using the integral intensities of the respective $\mathrm{H}-1$ signals and was found to be 2:1:1. These data were consistent with those obtained previously for many other FucCS bearing sulfated fucosyl branches $[17,24-30]$. 
Table 1. The data of ${ }^{1} \mathrm{H}$ and ${ }^{13} \mathrm{C}$ NMR spectra of fucosylated chondroitin sulfate $\mathrm{CD}$ and chondroitin sulfate SS (the bold numerals indicate the positions of sulfate). The residues are designated as in Figure 4.

\begin{tabular}{|c|c|c|c|c|c|c|}
\hline Residue & $\mathrm{H} 1 / \mathrm{C} 1$ & $\mathrm{H} 2 / \mathrm{C} 2$ & H3/C3 & $\mathrm{H} 4 / \mathrm{C} 4$ & $\mathrm{H} 5 / \mathrm{C} 5$ & H6/C6 \\
\hline $\mathbf{A} \rightarrow 4)-\beta-D-G l c p A-(1 \rightarrow$ & $4.48 / 105.0$ & $3.64 / 75.0$ & $3.71 / 78.1$ & $3.96 / 76.6$ & $3.71 / 78.1$ & $\begin{array}{c}- \\
176.0\end{array}$ \\
\hline $\left.\mathbf{A}^{\prime} \rightarrow 4\right)-\beta-\mathrm{D}-\mathrm{Glc} p \mathrm{~A}-(1 \rightarrow$ & $4.48 / 105.0$ & $3.60 / 75.0$ & $3.68 / 80.7$ & $4.00 / 76.6$ & $3.71 / 78.1$ & $\begin{array}{c}- \\
176.0\end{array}$ \\
\hline B $\rightarrow 3)-\beta$-D-GalpNAc4S6S-( $1 \rightarrow$ & $4.58 / 100.9$ & $4.07 / 52.7$ & $3.95 / 77.9$ & $4.81 / 77.2$ & $4.00 / 73.2$ & $\begin{array}{c}4.33,4.20 \\
68.5\end{array}$ \\
\hline $\mathrm{C} \rightarrow 3)-\beta-D-G a l p N A c 4 S-(1 \rightarrow$ & $4.58 / 100.9$ & $4.07 / 52.7$ & $3.95 / 77.9$ & $4.81 / 77.2$ & $4.02 / 76.2$ & $3.81 / 62.3$ \\
\hline $\mathbf{D} \alpha$-L-Fuc $p 2 S 4 S-(1 \rightarrow$ & $5.69 / 97.7$ & $4.48 / 76.6$ & $4.17 / 67.8$ & $4.86 / 82.5$ & $4.90 / 67.5$ & $1.37 / 16.9$ \\
\hline E $\alpha$-L-Fucp $3 S 4 S-(1 \rightarrow$ & $5.34 / 100.5$ & $3.95 / 67.6$ & $4.53 / 76.6$ & $5.01 / 80.6$ & $4.80 / 67.6$ & $1.37 / 17.2$ \\
\hline F $\alpha$-L-Fuc $p 4 S-(1 \rightarrow$ & $5.41 / 99.6$ & $3.82 / 69.7$ & $4.04 / 70.0$ & $4.77 / 82.4$ & $4.80 / 67.6$ & $1.37 / 17.2$ \\
\hline G $\rightarrow 4)-\beta$-D-Glc $p$ A- $(1 \rightarrow$ & $4.47 / 105.1$ & $3.38 / 73.9$ & $3.59 / 75.2$ & $3.78 / 81.8$ & $3.70 / 77.9$ & $\begin{array}{c}- \\
175.9\end{array}$ \\
\hline $\left.\mathrm{G}^{\prime} \rightarrow 4\right)-\beta-\mathrm{D}-\mathrm{Glc} p \mathrm{~A}-(1 \rightarrow$ & $4.50 / 105.3$ & $3.38 / 73.9$ & $3.59 / 75.2$ & $3.74 / 82.9$ & $3.70 / 77.9$ & $\begin{array}{c}- \\
175.7\end{array}$ \\
\hline $\mathbf{H} \rightarrow 3)-\beta$-D-Gal $p$ NAc $4 S 6 S$ - $(1 \rightarrow$ & $4.59 / 102.4$ & $4.03 / 52.8$ & $4.03 / 76.8$ & $4.75 / 77.6$ & $4.12 / 74.0$ & $4.24 / 68.9$ \\
\hline $\mathbf{J} \rightarrow 3)-\beta-\mathrm{D}-G a l p N A c 4 S-(1 \rightarrow$ & $4.59 / 102.4$ & $4.03 / 52.8$ & $4.03 / 76.8$ & $4.75 / 77.6$ & $3.83 / 75.8$ & $3.80 / 62.3$ \\
\hline $\mathbf{K} \rightarrow 3)-\beta-\mathrm{D}-$ Gal $p$ NAc6S- $(1 \rightarrow$ & $4.56 / 102.6$ & $4.03 / 52.3$ & $3.86 / 81.5$ & $4.18 / 68.9$ & $3.98 / 74.0$ & $4.24 / 68.9$ \\
\hline
\end{tabular}




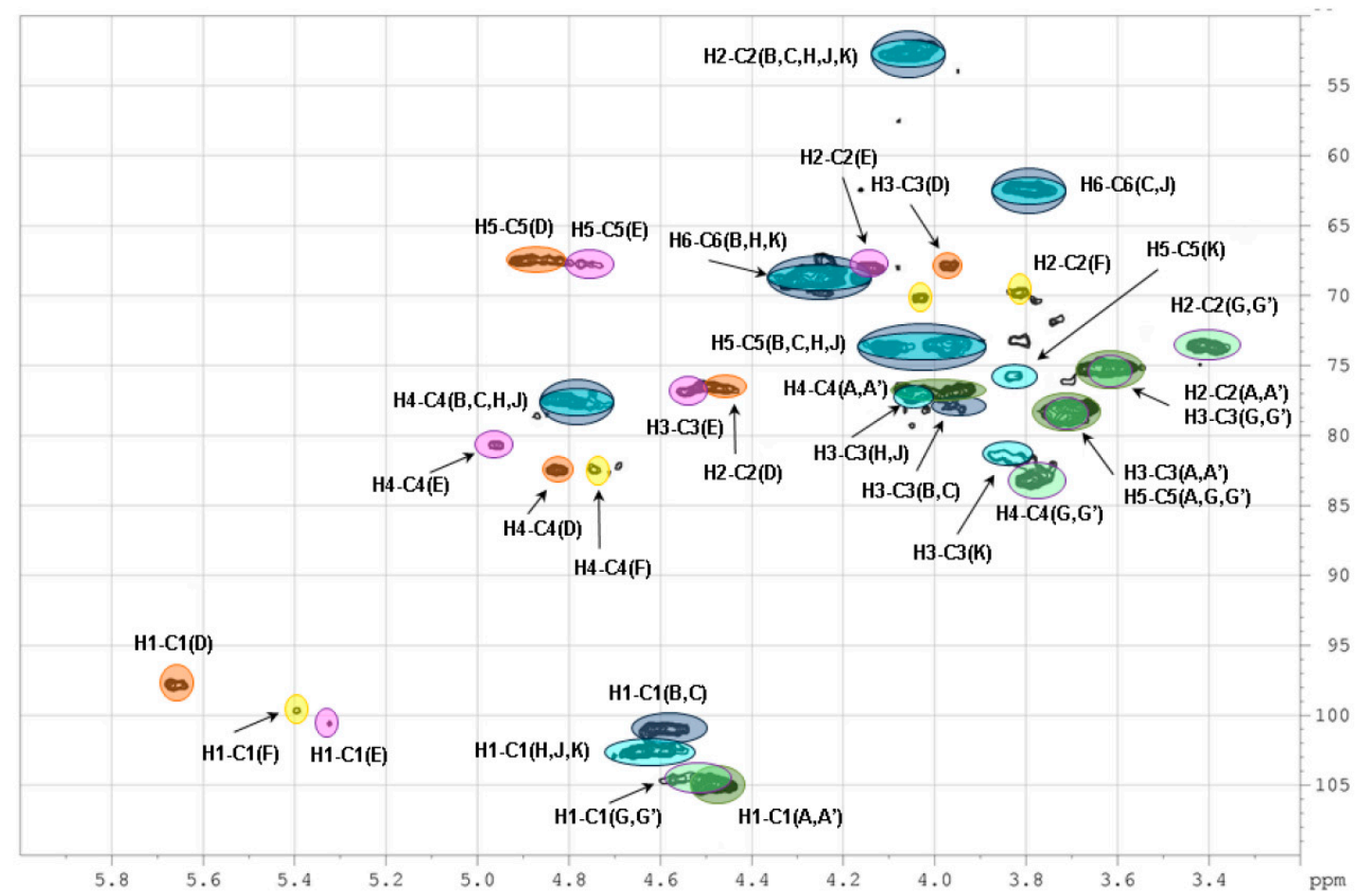

A

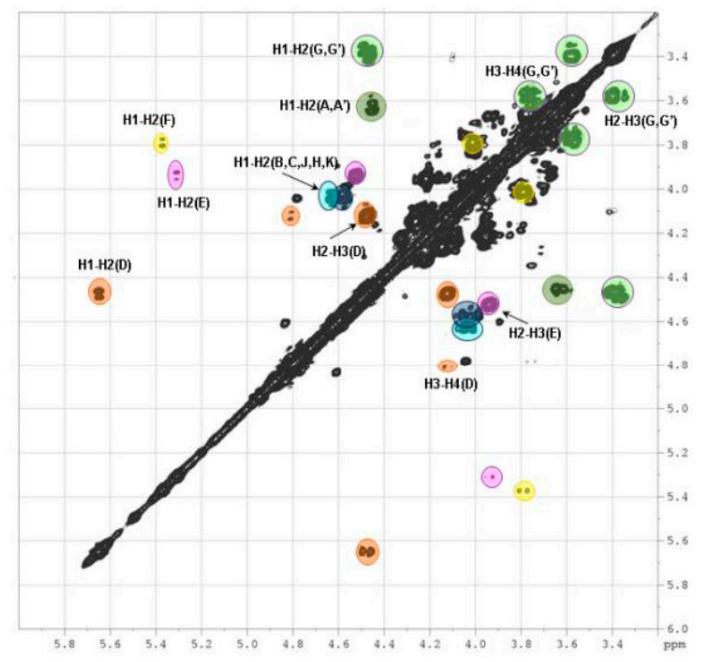

B

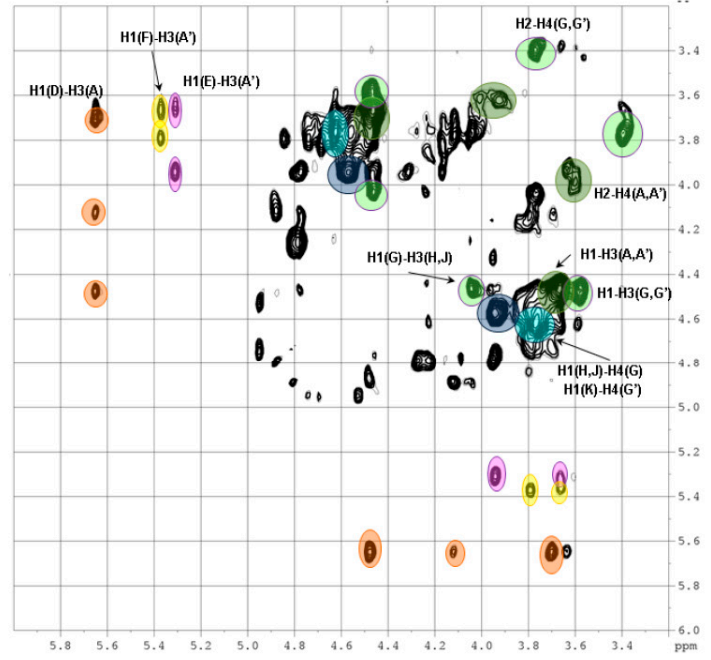

C

Figure 5. The NMR spectra of fucosylated chondroitin sulfate CD: ${ }^{1} \mathrm{H}_{-}{ }^{13} \mathrm{C}$ HSQC $(\mathbf{A}),{ }^{1} \mathrm{H}-{ }^{1} \mathrm{H}$ COSY (B), ROESY (C). Correlation peaks are marked in the spectra by letter designation of units used in Figure 4 and Table 1.

Two other cross-peaks $\mathrm{H}_{1} / \mathrm{C}_{1} 4.47 / 105.1 \mathrm{ppm}$ and 4.58/100.9 ppm in the ${ }^{1} \mathrm{H}_{-}{ }^{13} \mathrm{C}$ HSQC spectrum are related to the units GlcA $\left(\mathbf{A}, \mathbf{A}^{\prime}\right)$ and GalNAc $(\mathbf{B}, \mathbf{C})$, respectively, which are typical components of a backbone $[\rightarrow 3)-\beta-D-G a l N A c-(1 \rightarrow 4)-\beta-D-G l c A-(1 \rightarrow]_{n}$ of fucosylated chondroitin sulfates $[9-14,17]$. The assignment of ${ }^{1} \mathrm{H}$ signals in the spin-systems of units $\mathbf{A}, \mathbf{A}^{\prime}, \mathbf{B}$ and $\mathbf{C}$ was performed based on the data of COSY, ROESY (Figure 5B,C), and TOCSY (Figure S5) spectra (Table 1). The respective ${ }^{13} \mathrm{C}$ signals were easily determined using the HSQC spectrum.

The unusual cross-peak $\mathrm{H}_{1} / \mathrm{C}_{1}(4.56-4.59) /(102.4-102.6) \mathrm{ppm}$ in the HSQC spectrum was found to be related to the GalNAc units $(\mathbf{H}, \mathbf{J}, \mathbf{K})$. Thus, the respective correlation $\mathrm{H}_{1} / \mathrm{H}_{2}$ in the COSY spectrum indicated the position of $\mathrm{H}_{2}$ at $4.03 \mathrm{ppm}$, which is typical for the GalNAc units (Figure 5B). Moreover, 
the COSY spectrum led to reveal another type of the GlcA units in a structure of CD. Besides units $A$ and $\mathbf{A}^{\prime}$ described above, there were residues $\mathbf{G}$ and $\mathbf{G}^{\prime}$ having $\mathrm{H}_{1}$ and $\mathrm{C}_{1}$ signals overlapped with those of $\mathbf{A}$ and $\mathbf{A}^{\prime}$. As the result, the seventh cross-peak $H_{1} / C_{1}$ related to $G / G^{\prime}$ residues was masked in the HSQC spectrum. Fortunately, the values of chemical shifts of other signals of $\mathbf{G}\left(\mathbf{G}^{\prime}\right)$ were significantly different, indicating the distinction in substitution of units $\mathbf{A}\left(\mathbf{A}^{\prime}\right)$ and $\mathbf{G}\left(\mathbf{G}^{\prime}\right)$ (Table 1). The high field shifts of $C_{2}(73.9 \mathrm{ppm})$ and $C_{3}(75.2 \mathrm{pm})$ signals pointed the lack of any substituents in these positions, while the low field shift of $C_{4}$ signal $(81.8$ and $82.9 \mathrm{ppm})$ supported the presence of $(1 \rightarrow 4)$-linkage. The connections between GalNAc units and GlcA units was determined by the cross-peaks $\mathrm{H}_{1}(\mathrm{GalNAc})-\mathrm{H}_{4}(\mathrm{GlcA})$ and $\mathrm{H}_{1}(\mathrm{GlcA})-\mathrm{H}_{3}(\mathrm{GalNAc})$ in the ROESY spectrum (Figure $\left.5 \mathrm{C}\right)$. Therefore, linear fragments composed of the disaccharides $\rightarrow 3)-\beta-D-G a l N A c 4 S 6 S-(1 \rightarrow 4)-\beta$-D-GlcA- $(1 \rightarrow$, $\rightarrow 3)$ - $\beta$-D-GalNAc4S- $(1 \rightarrow 4)-\beta$-D-GlcA- $(1 \rightarrow$, and $\rightarrow 3)-\beta$-D-GalNAc6S- $(1 \rightarrow 4)-\beta$-D-GlcA- $(1 \rightarrow$ were found in CD. To confirm the presence of unsubstituted both at O-2 and O-3 glucuronic acid residues in the structure of $\mathrm{CD}$ we compared its spectra with those of chondroitin sulfate SS bearing such structural motive (Figure 2 and Figures S1-S4). Coincidence of the respective signals successfully evidenced the presence of linear fragments in a structure of $\mathrm{CD}$. The ratio of the linear and branched blocks was calculated using the values of integral intensity of the $\mathrm{H} 1 / \mathrm{C} 1$ cross-peaks of units $(\mathbf{B}, \mathbf{C})$ and $(\mathbf{H}, \mathbf{J}, \mathbf{K})$ in the HSQC NMR spectrum and was found to be about 2:3.

Chondroitin sulfates are known as complex molecules demonstrating a wide range of biological activities [31], including anti-inflammatory action [32]. Previously several chondroitin sulfates obtained from fish cartilages were studied as anti-inflammatory agents, using a model of acute peritoneal inflammation in rats [21]. It was interesting to compare anti-inflammatory properties of typical vertebrate chondroitin sulfate and fucosylated chondroitin sulfate from sea cucumber. For this purpose, purified chondroitin sulfate SS was prepared from cartilage of the fish S. salar. Two polysaccharides CD and SS were studied as anti-inflammatory agents in vivo on a model of acute peritoneal inflammation in rats. The acute inflammatory response is characterized by tissue influx of neutrophilic granulocytes (neutrophils), which are considered as main effectors at the beginning stage [33,34]. The number of neutrophils in the exudate was calculated after $3 \mathrm{~h}$ of inflammation (Table 2). About $45 \%$ inhibition was found for $\mathbf{C D}$, while structurally related chondroitin sulfate SS demonstrated only $31 \%$ inhibition indicating that structural features of $\mathbf{C D}$, primarily the presence of fucosyl branches and greater degree of sulfation, are essential for more pronounced anti-inflammatory effect. More detailed immunological study of the anti-inflammatory effect of FCS will be described further with the use of a series of structurally different polysaccharides from several sea cucumber species.

Table 2. Anti-inflammatory activity of the polysaccharides SS and CD.

\begin{tabular}{ccccc}
\hline Sample & Number of Animals & Number of Neutrophils $\left(\times \mathbf{1 0}^{\mathbf{6}}\right)$ & $\mathbf{p}$ & \% of Inhibition \\
\hline Control & 6 & $69.4 \pm 6.4$ & & - \\
SS & 4 & $47.8 \pm 5.2$ & $<0.002$ & 31.2 \\
CD & 4 & $38.2 \pm 4.9$ & $<0.002$ & 45.0 \\
\hline
\end{tabular}

\section{Materials and Methods}

\subsection{General Methods}

Quantitative determination of monosaccharides by hydrolysis in $2 \mathrm{M} \mathrm{CF}_{3} \mathrm{COOH}$ at $100{ }^{\circ} \mathrm{C}$ for $8 \mathrm{~h}$ followed by transformation into alditol acetates and gas-liquid chromatography, as well as turbidimetric determination of sulfate were carried out as described previously $[35,36]$. For determination of hexosamines acid hydrolysis in $6 \mathrm{~N} \mathrm{HCl}$ at $100{ }^{\circ} \mathrm{C}$ for $6 \mathrm{~h}$ was used. Glucuronic acid was estimated colorimetrically with 3,5-dimethylphenol [37]. Molecular weight of the polysaccharide was estimated

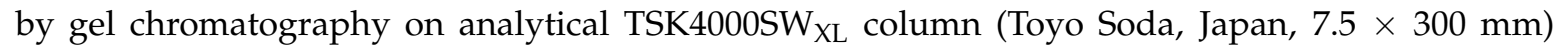
calibrated using pullulans (Fluka) and eluted with $1 \mathrm{M} \mathrm{NaCl}$. 


\subsection{Isolation of Polysaccharide $C D$}

The sea cucumber Cucumaria djakonovi (Baranova, 1980), family Cucumariidae, order Dendrochirotida, was collected by diving on 14 September 2016 from Kamchatka coastal waters (Avachinsky Gulf near Starichkov Island, at 52.46 $203^{\prime}$ N, $158.37^{\circ} 362^{\prime} \mathrm{E}$, depth $20 \mathrm{~m}$ ) and fixed with ethanol. The specimen was identified by one of the authors (E.G.Panina), preparation No. 759 is deposited at the Kamchatka Branch of Pacific Geographical Institute FEB RAS, PetropavlovskKamchatsky 683000, Russia. According to the conventional procedure [20], the wet body walls (19.3 g) were minced, suspended in $200 \mathrm{~mL}$ of $0.1 \mathrm{M}$ sodium acetate buffer $\mathrm{pH} 6.0$ containing papain $(0.7 \mathrm{~g})$, EDTA $(0.3 \mathrm{~g})$ and L-cysteine hydrochloride $(0.2 \mathrm{~g})$, and incubated at $45-50{ }^{\circ} \mathrm{C}$ for $24 \mathrm{~h}$. An aqueous solution of hexadecyltrimetylammonium bromide $(10 \%, 60 \mathrm{~mL})$ was added to the filtered extract, the resulting precipitate was stirred with $20 \%$ ethanolic NaI solution $(5 \times 50 \mathrm{~mL})$ for $2-3$ days, washed with ethanol, dissolved in water, filtered and lyophilized to give crude polysaccharide preparation SP, yield $219 \mathrm{mg}$, composition: Fucose, 8.0\%, galactosamine, 5.7\%, uronic acids, 5.5\%, galactose, 5.8\%, glucose, $3.0 \%$, glucosamine, $1.9 \%$, and sulfate, $28.3 \%$.

A solution of SP $(200 \mathrm{mg})$ in water $(50 \mathrm{~mL})$ was placed on a column $(3 \times 10 \mathrm{~cm})$ with DEAE-Sephacel in $\mathrm{Cl}^{-}$-form and eluted with water, followed by $\mathrm{NaCl}$ solutions of increasing concentration $(0.5,0.75$, 1.0 and $1.5 \mathrm{M}$ ), each time up to the absence of a positive reaction of eluate for carbohydrate [38]. Eluate at $1.0 \mathrm{M} \mathrm{NaCl}$ was desalted on Sephadex G-15 and lyophilized giving rise to preparation CD (56 mg). The polysaccharide contained Fuc, GalNAc, GlcA and sulfate in a molar ratio of 11:16:16:57 with negligible content of other monosaccharides.

\subsection{Purification of Polysaccharide SS}

A crude extract from cartilage of Salmo salar [21] (100 mg) was dissolved in water (2 mL) and $1 \mathrm{M}$ aq $\mathrm{NaOH}$ solution $(0.1 \mathrm{~mL})$ was added. The mixture was kept for $3 \mathrm{~h}$ at $40{ }^{\circ} \mathrm{C}$. Then the solution was neutralized by $0.1 \mathrm{M} \mathrm{HCl}$ and placed on a column containing DEAE-Sephacel in $\mathrm{Cl}^{-}$-form. The column was eluted with water followed by $\mathrm{NaCl}$ solutions of increasing concentration $(0.5,0.75,1.0$ and $1.5 \mathrm{M})$, each time up to the absence of a positive reaction of eluate for carbohydrate [38]. Eluate at $1.0 \mathrm{M} \mathrm{NaCl}$ was desalted on Sephadex G-15 column and lyophilized to give polysaccharide SS (40 mg).

\subsection{Polyacrylamide Gel Electrophoresis (PAGE)}

The polysaccharides CD, SS, heparin (Sigma-Aldrich, St. Louis, MO, USA) and enoxaparin (Clexane $^{\circledR}$, Sanofi, Paris, France) $(15 \mu \mathrm{g})$ were applied to a 0.75 -mm-thick layer of $10 \%$ polyacrylamide (ICN Biochemicals), $100 \mathrm{mM}$ Tris-borate, $\mathrm{pH} 8.3$ gel in a buffer $(10 \mathrm{mM}$ Tris-borate, $\mathrm{pH} 8.3)$ with $10 \%(w / v)$ of glycerol. Electrophoresis was run at $400 \mathrm{~V}$ in a buffer (100 mM Tris-borate, $\mathrm{pH}$ 8.3) during $1 \mathrm{~h}$. The gel was stained with $0.003 \%$ Stains-all (Merck, DE) in formamide (Sigma, EUA) - isopropanol—water (5:25:70) overnight in the dark and destained with water. The results are presented on Figure 1.

\subsection{NMR Spectroscopy}

The sample CD (30 mg) were dissolved in $99.9 \% \mathrm{D}_{2} \mathrm{O}$, freeze-dried, dissolved in $99.96 \% \mathrm{D}_{2} \mathrm{O}$ and put into Shigemi tube. The value of $\mathrm{pH}$ was adjusted to 7.0 by addition of $0.01 \mathrm{M} \mathrm{NaOD}$ solution in $\mathrm{D}_{2} \mathrm{O}$. The 1D and 2D NMR spectra of the samples in $\mathrm{D}_{2} \mathrm{O}$ were recorded on a $600 \mathrm{MHz}$ Avance II (Bruker, Germany) NMR spectrometer equipped with a z-gradient probe with proton and carbon frequencies of 600.13 and $150.90 \mathrm{MHz}$ respectively. 3-(Trimethylsilyl)-2,2,3,3-tetradeuteropropionic acid (TSP) was used as an internal standard $\left(\delta_{\mathrm{H}} 0.0 \mathrm{ppm}, \delta_{\mathrm{C}}-1.6 \mathrm{ppm}\right)$. The conditions of the experiments were described previously [12]. 


\subsection{Model of Acute Peritoneal Inflammation in Rats}

The animal protocols used in this work were evaluated and approved by the local ethical committee of the V.N. Orekhovich Research Institute of Biomedical Chemistry (Protocol 04-2018). They are in accordance with the order 490 (5 November 2008) of the Agricultural Ministry of Russian Federation, meet National GLP Standard of Russian Federation (53434-2009).

The peritoneal inflammation in rats was performed according to a method described earlier [39,40]. A $9.0 \%$ solution of peptone in $0.9 \% \mathrm{NaCl}(8 \mathrm{~mL})$ was administered intraperitoneally to female Wistar rats (ca. $250 \mathrm{~g}$ ) under ether narcosis. Solutions of polysaccharides CD and SS (1 mg in $0.3 \mathrm{~mL}$ of sterile $0.9 \% \mathrm{NaCl}$ ) were administered to a rat femoral vein under ether narcosis $15 \mathrm{~min}$ after the injection of peptone. Sterile $0.9 \% \mathrm{NaCl}(0.3 \mathrm{~mL})$ was administered intravenously to control animals. After $3 \mathrm{~h}$, the animals were decapitated under ether narcosis. The abdominal cavity was washed with a medium $(30 \mathrm{~mL})$ containing PBS, heparin $(60$ unit $/ \mathrm{mL}), 0.02 \%$ EDTA, and $0.03 \%$ bovine serum with intense peritoneal massage. The total cell number in the washing liquid was counted in Goryaev's chamber. To calculate the number of neutrophils, the cell suspension was centrifuged at $400 \mathrm{~g}$ for $10 \mathrm{~min}$. The concentrated suspension was diluted with a whole bovine serum (1:1). Smears were made and stained by the May Grünwald Giemsa method. The percentage of neutrophils in the smears was determined by counting of 6-8 hundred cells using a double blind method. The total number of neutrophils in the exudate was calculated from the percentage of neutrophils and the total cell number. Data in the group were presented in the format of mean and standard deviation $(\mathrm{Mean} \pm \mathrm{SD}$ ). Analysis of the reliability of differences was carried out using the $\mathrm{t}$-criterion. Differences were considered significant at $p<0.05$.

\section{Conclusions}

Fucosylated chondroitin sulfates (FucCS) are specific components of the holothurian body walls. Structural analysis of FucCS is mainly based on the data of NMR spectroscopy [23,41,42]. Fine structures of FucCS depend on the sea cucumber species [7,8]. Isolation and structural analysis of new representatives of FucCS give new evidence on the structural diversity of this important class of sulfated glycosaminoglycans. Thus, a new polysaccharide (CD) was found in Cucumaria djakonovi, the holothurian species collected from Kamchatka coastal waters. As followed unambiguously from the NMR spectra of $\mathbf{C D}$, the polysaccharide contained, side by side with usual repeating multiple sulfated trisaccharide units $\alpha$-L-Fuc- $(1 \rightarrow 3)-\beta$-D-GlcA- $(1 \rightarrow 3)-\beta$-D-GalNAc, also substantial amount of disaccharide repeating units $\beta$-D-GlcA- $(1 \rightarrow 3)-\beta-D-G a l N A c$ sulfated at O-4, O- 6 or both at O-4 and O-6 of GalNAc (units of chondroitin sulfates A, C and E, respectively), typical of chondroitin sulfates (CS) of vertebrates, where GlcA residues bear no substituents both at $\mathrm{O}-2$ and $\mathrm{O}-3$. Among various biological activities described for CS and FucCS, marked anti-inflammatory action of these polysaccharides was found and explained by their possible interaction with P- and L-selectins $[17,21,43]$. Comparison of anti-inflammatory activity of CD and SS (a linear CS isolated from the fish Salmo salar cartilage) made it possible to demonstrate the enhanced biological activity of molecules bearing sulfated fucosyl branches.

Supplementary Materials: The following are available online at http:/ /www.mdpi.com/1660-3397/16/10/389/ s1, Figure S1: The ${ }^{1} \mathrm{H}$ NMR (A) and ${ }^{13} \mathrm{C}$ NMR (B) spectra of chondroitin sulfate SS, Figure S2: The ${ }^{1} \mathrm{H}_{-}{ }^{13} \mathrm{C}$ HSQC NMR spectrum of chondroitin sulfate SS, Figure S3: The ${ }^{1} \mathrm{H}^{1}{ }^{1} \mathrm{H}$ COSY NMR spectrum of chondroitin sulfate SS, Figure S4: The HMBC spectra of chondroitin sulfate SS (A) and fucosylated chondroitin sulfate CD (B). Figure S5: The ${ }^{1} \mathrm{H}^{-1} \mathrm{H}$ TOCSY NMR spectrum of fucosylated chondroitin sulfate $\mathrm{CD}$.

Author Contributions: Conceptualization, A.I.U., N.E.N. and N.E.U.; methodology, A.I.U., M.I.B., N.E.U., E.A.T., E.G.P., N.P.S., N.A.U.; analysis, M.I.B., N.E.U., E.A.T., N.A.U., A.S.D., A.S.S.; investigation, M.I.B., N.E.U., A.S.D., A.S.S., A.I.U.; resources, E.G.P., N.P.S.; writing-original draft preparation, N.E.U., A.I.U.; writing-review and editing, all authors; supervision, A.I.U., N.E.N.

Funding: This research was funded by RUSSIAN SCIENCE FOUNDATION, grant number 14-13-01325. 
Conflicts of Interest: The authors declare no conflict of interest. The funders had no role in the design of the study; in the collection, analyses, or interpretation of data; in the writing of the manuscript, or in the decision to publish the results.

\section{References}

1. Wu, M.; Xu, L.; Zhao, L.; Xiao, C.; Gao, N.; Luo, L.; Yang, L.; Li, Z.; Chen, L.; Zhao, J. Structural analysis and anticoagulant activities of the novel sulfated fucan possessing a regular well-defined repeating unit from sea cucumber. Mar. Drugs 2015, 13, 2063-2084. [CrossRef] [PubMed]

2. Yu, L.; Xue, C.; Chang, Y.; Hu, Y.; Xu, X.; Ge, L.; Liu, G. Structure and rheological characteristics of fucoidan from sea cucumber Apostichopus japonicus. Food Chem. 2015, 180, 71-76. [CrossRef] [PubMed]

3. Hu, Y.; Li, S.; Li, J.; Ye, X.; Ding, T.; Liu, D.; Chen, J.; Ge, Z.; Chen, S. Identification of a highly sulfated fucoidan from sea cucumber Pearsonothuria graeffei with well-repeated tetrasaccharide units. Carbohydr. Polym. 2015, 134, 808-816. [CrossRef] [PubMed]

4. Chang, Y.; Hu, Y.; Yu, L.; McClements, D.J.; Xu, X.; Liu, G.; Xue, C. Primary structure and chain conformation of fucoidan extracted from sea cucumber Holothuria tubulosa. Carbohyd. Polym. 2016, 136, 1091-1097. [CrossRef] [PubMed]

5. Li, S.; Li, J.; Zhi, Z.; Wei, C.; Wang, W.; Ding, T.; Ye, X.; Hu, Y.; Linhardt, R.J.; Chen, S. Macromolecular properties and hypolipidemic effects of four sulfated polysaccharides from sea cucumbers. Carbohydr. Polym. 2017, 173, 330-337. [CrossRef] [PubMed]

6. Ustyuzhanina, N.E.; Bilan, M.I.; Dmitrenok, A.S.; Borodina, E.Y.; Nifantiev, N.E.; Usov, A.I. A highly regular fucan sulfate from the sea cucumber Stichopus horrens. Carbohydr. Res. 2018, 456, 5-9. [CrossRef] [PubMed]

7. Pomin, V.H. Holothurian fucosylated chondroitin sulfates. Mar. Drugs 2014, 12, 232-254. [CrossRef] [PubMed]

8. Myron, P.; Siddiquee, S.; Azad, S.A. Fucosylated chondroitin sulfate diversity in sea cucumbers: A review. Carbohydr. Polym. 2014, 112, 173-178. [CrossRef] [PubMed]

9. Ustyuzhanina, N.E.; Bilan, M.I.; Dmitrenok, A.S.; Shashkov, A.S.; Kusaykin, M.I.; Stonik, V.A.; Nifantiev, N.E.; Usov, A.I. Structure and biological activity of a fucosylated chondroitin sulfate from the sea cucumber Cucumaria japonica. Glycobiology 2016, 26, 449-459. [CrossRef] [PubMed]

10. Ustyuzhanina, N.E.; Bilan, M.I.; Dmitrenok, A.S.; Tsvetkova, E.A.; Shashkov, A.S.; Stonik, V.A.; Nifantiev, N.E.; Usov, A.I. Structural characterization of fucosylated chondroitin sulfates from sea cucumbers Apostichopus japonicus and Actinopyga mauritiana. Carbohydr. Polym. 2016, 153, 399-405. [CrossRef] [PubMed]

11. Ustyuzhanina, N.E.; Bilan, M.I.; Dmitrenok, A.S.; Nifantiev, N.E.; Usov, A.I. Two fucosylated chondroitin sulfates from the sea cucumber Eupentacta fraudatrix. Carbohydr. Polym. 2017, 164, 8-12. [CrossRef] [PubMed]

12. Ustyuzhanina, N.E.; Bilan, M.I.; Dmitrenok, A.S.; Shashkov, A.S.; Nifantiev, N.E.; Usov, A.I. The structure of a fucosylated chondroitin sulfate from the sea cucumber Cucumaria frondosa. Carbohydr. Polym. 2017, 165, 7-12. [CrossRef] [PubMed]

13. Ustyuzhanina, N.E.; Bilan, M.I.; Dmitrenok, A.S.; Borodina, E.Y.; Stonik, V.A.; Nifantiev, N.E.; Usov, A.I. A highly regular fucosylated chondroitin sulfate from the sea cucumber Massinium magnum: Structure and effects on coagulation. Carbohydr. Polym. 2017, 167, 20-26. [CrossRef] [PubMed]

14. Ustyuzhanina, N.E.; Bilan, M.I.; Dmitrenok, A.S.; Shashkov, A.S.; Nifantiev, N.E.; Usov, A.I. Two structurally similar fucosylated chondroitin sulfates from the holothurian species Stichopus chloronotus and Stichopus horrens. Carbohydr. Polym. 2018, 189, 10-14. [CrossRef] [PubMed]

15. Pomin, V.H.; Mourão, P.A.S. Specific sulfation and glycosylation-A structural combination for the anticoagulation of marine carbohydrates. Front. Cell. Infect. Microbiol. 2014, 4, 33. [CrossRef] [PubMed]

16. Mou, J.; Li, Q.; Qi, X.; Yang, J. Structural comparison, antioxidant and anti-inflammatory properties of fucosylated chondroitin sulfate of three edible sea cucumbers. Carbohydr. Polym. 2018, 185, 41-47. [CrossRef] [PubMed]

17. Panagos, C.G.; Thomson, D.S.; Moss, C.; Hoghes, A.D.; Kelly, M.S.; Liu, Y.; Chai, W.; Venkatasamy, R.; Spina, D.; Page, C.P.; et al. Fucosylated chondroitin sulfates from the body wall of the sea cucumber Holothuria forskali. Conformation, selectin binding, and biological activity. J. Biol. Chem. 2014, 289, 28284-28298. [CrossRef] [PubMed] 
18. Santos, G.R.C.; Glauser, B.F.; Parreiras, L.A.; Vilanova, E.; Mourão, P.A.S. Distinct structures of the $\alpha$-fucose branches in fucosylated chondroitin sulfates do not affect their anticoagulant activity. Glycobiology 2015, 25, 1043-1052. [CrossRef] [PubMed]

19. Stepanov, V.G.; Panina, E.G.; Shaporev, R.A. Species composition of the sea cucumbers (Holothuroidea) in the Far-Eastern seas of Russia, VIII: The amount of taxons, general character of placement. Bull. Kamchatka State Tech. Univ. 2016, 36, 88-96. [CrossRef]

20. Vieira, R.P.; Mulloy, B.; Mourão, P.A.S. Structure of a fucose-branched chondroitin sulfate from sea cucumber. Evidence for the presence of 3-O-sulfo- $\beta$-D-glucuronosyl residues. J. Biol. Chem. 1991, 266, 13530-13536. [PubMed]

21. Krylov, V.B.; Grachev, A.A.; Ustyuzhanina, N.E.; Ushakova, N.A.; Preobrazhenskaya, M.E.; Kozlova, N.I.; Portsel, M.N.; Konovalova, I.N.; Novikov, V.Y.; Siebert, H.-C.; et al. Preliminary structural characterization, anti-inflammatory and anticoagulant activities of chondroitin sulfates from marine fish cartilage. Russ. Chem. Bull. Int. Ed. 2011, 60, 746-753. [CrossRef]

22. Maccari, F.; Ferrarini, F.; Volpi, N. Structural characterization of chondroitin sulfate from sturgeon bone. Carbohydr. Res. 2010, 345, 1575-1580. [CrossRef] [PubMed]

23. Mucci, A.; Schenetti, L.; Volpi, N. ${ }^{1} \mathrm{H}$ and ${ }^{13} \mathrm{C}$ nuclear magnetic resonance identification and characterization of components of chondroitin sulfates of various origin. Carbohydr. Polym. 2000, 41, 37-45. [CrossRef]

24. Chen, S.; Xue, C.; Yin, L.; Tang, Q.; Yu, G.; Chai, W. Comparison of structures and anticoagulant activities of fucosylated chondroitin sulfates from different sea cucumbers. Carbohydr. Polym. 2011, 83, 688-696. [CrossRef]

25. Gao, N.; Lu, F.; Xiao, C.; Yang, L.; Chen, J.; Zhou, K.; Wen, D.; Li, Z.; Wu, M.; Jiang, J.; et al. $\beta$-Eliminative depolymerization of the fucosylated chondroitin sulfate and anticoagulant activities of resulting fragments. Carbohydr. Polym. 2015, 127, 427-437. [CrossRef] [PubMed]

26. Wu, M.; Huang, R.; Wen, D.; Gao, N.; He, J.; Li, Z.; Zhao, J. Structure and effect of sulfated fucose branches on anticoagulant activity of the fucosylated chondroitin sulfate from sea cucumber Thelenata ananas. Carbohydr. Polym. 2012, 87, 862-868. [CrossRef]

27. Wu, N.; Ye, X.; Guo, X.; Liao, N.; Yin, X.; Hu, Y.; Sun, Y.; Liu, D.; Chen, S. Depolymerization of fucosylated chondroitin sulfate from sea cucumber, Pearsonothuriagraeffei, via ${ }^{60}$ Co irradiation. Carbohydr. Polym. 2013, 93, 604-614. [CrossRef] [PubMed]

28. Yang, J.; Wang, Y.; Jiang, T.; Lv, Z. Novel branch patterns and anticoagulant activity of glycosaminoglycan from sea cucumber Apostichopus japonicus. Int. J. Biol. Macromol. 2015, 72, 911-918. [CrossRef] [PubMed]

29. Yang, J.; Mou, J.; Ding, D.; Wang, X. In vivo and in vitro antithrombus activities of depolymerized holothurian polysaccharides. Int. J. Biol. Macromol. 2017, 94, 364-369. [CrossRef] [PubMed]

30. Yoshida, K.; Minami, Y.; Nemoto, H.; Numata, K.; Yamanaka, E. Structure of DHG, a depolymerized glycosaminoglycan from sea cucumber Stichopus japonicus. Tetrahedron Lett. 1992, 33, 4959-4962. [CrossRef]

31. Lauder, R.M. Chondroitin sulphate: A complex molecule with potential impact on a wide range of biological systems. Compl. Ther. Med. 2009, 17, 56-62. [CrossRef] [PubMed]

32. Volpi, N. Anti-inflammatory activity of chondroitin sulphate: New functions from an old natural macromolecule. Inflammopharmacology 2011, 19, 299-306. [CrossRef] [PubMed]

33. Geering, B.; Stoeckle, C.; Conus, S.; Simon, H.U. Living and dying for inflammation: Neutrophils, eosinophils, basophils. Trends Immunol. 2013, 34, 398-409. [CrossRef] [PubMed]

34. Vermeren, S.; Miles, K.; Chu, J.Y.; Salter, D.; Zamoyska, R.; Gray, M. PTPN22 is a critical regulator of Fc $\gamma$ receptor-mediated neutrophil activation. J. Immunol. 2016, 197, 4771-4779. [CrossRef] [PubMed]

35. Bilan, M.I.; Grachev, A.A.; Ustuzhanina, N.E.; Shashkov, A.S.; Nifantiev, N.E.; Usov, A.I. Structure of a fucoidan from the brown seaweed Fucus evanescens C.Ag. Carbohydr. Res. 2002, 337, 719-730. [CrossRef]

36. Bilan, M.I.; Zakharova, A.N.; Grachev, A.A.; Shashkov, A.S.; Nifantiev, N.E.; Usov, A.I. Polysaccharides of algae: 60. Fucoidan from the Pacific brown alga Analipus japonicus (Harv.) Winne (Ectocarpales, Scytosiphonaceae). Russ. J. Bioorg. Chem. 2007, 33, 38-46. [CrossRef]

37. Usov, A.I.; Bilan, M.I.; Klochkova, N.G. Polysaccharides of algae: 48. Polysaccharide composition of several calcareous red algae: Isolation of alginate from Corallina pilulifera P. et R. (Rhodophyta, Corallinaceae). Bot. Mar. 1995, 38, 43-51.

38. Dubois, M.; Gilles, K.A.; Hamilton, J.K.; Rebers, P.A.; Smith, F. Colorimetric method for determination of sugars and related substances. Anal. Chem. 1956, 28, 350-356. [CrossRef] 
39. Croci, D.O.; Cumashi, A.; Ushakova, N.A.; Preobrazhenskaya, M.E.; Piccoli, A.; Totani, L.; Ustyuzhanina, N.E.; Bilan, M.I.; Usov, A.I.; Grachev, A.A.; et al. Fucans, but not fucomannoglucuronans, determine the biological activities of sulfated polysaccharides from Laminaria saccharina brown seaweed. PLoS ONE 2011, 6, e17283. [CrossRef] [PubMed]

40. Cumashi, A.; Ushakova, N.A.; Preobrazhenskaya, M.E.; D'Incecco, A.; Piccoli, A.; Totani, L.; Tinari, N.; Morozevich, G.E.; Berman, A.E.; Bilan, M.A.; et al. Comparative study of the anti-inflammatory, anticoagulant, antiangiogenic, and antiadhesive activities of nine different fucoidans from brown seaweeds. Glycobiology 2007, 17, 541-552. [CrossRef] [PubMed]

41. Pomin, V.H. NMR structural determination of unique invertebrate glycosaminoglycans endowed with medical properties. Carbohydr. Res. 2015, 413, 41-50. [CrossRef] [PubMed]

42. Mourão, P.A.S.; Vilanova, E.; Soares, P.A.G. Unveiling the structure of sulfated fucose-rich polysaccharides via nuclear magnetic resonance spectroscopy. Curr. Opin. Struct. Biol. 2018, 50, 33-41. [CrossRef] [PubMed]

43. Borsig, L.; Wang, L.; Cavalcante, M.C.; Cardilo-Reis, L.; Ferreira, P.L.; Mourão, P.A.S.; Esco, J.D.; Pavão, M.S. Selectin blocking activity of a fucosylated chondroitin sulfate glycosaminoglycan from sea cucumber. Effect on tumor metastasis and neutrophil recruitment. J. Biol. Chem. 2007, 282, 14984-14991. [CrossRef] [PubMed]

(C) 2018 by the authors. Licensee MDPI, Basel, Switzerland. This article is an open access article distributed under the terms and conditions of the Creative Commons Attribution (CC BY) license (http://creativecommons.org/licenses/by/4.0/). 